\title{
Metoprolol protects cardiomyocytes in rabbit model of heart failure by regulating $\mathrm{Cx} 43$
}

\author{
$\mathrm{HU}_{\mathrm{ZHAI}}{ }^{1-3}, \mathrm{WENYI} \mathrm{DAI}^{4}$ and $\mathrm{YU}_{\mathrm{WANG}}{ }^{1-3}$ \\ ${ }^{1}$ Department of Cardiology, Tianjin Third Central Hospital; ${ }^{2}$ Tianjin Key Laboratory of Artificial Cell, \\ Tianjin 300170; ${ }^{3}$ Artificial Cell Engineering Technology Research Center, Ministry of Health, Tianjin 300052; \\ ${ }^{4}$ Department of Cardiology, Tianjin Medical University General Hospital, Tianjin 300170, P.R. China
}

Received July 11, 2017; Accepted November 22, 2017

DOI: $10.3892 /$ etm.2017.5590

\begin{abstract}
This study investigated the protective effect of metoprolol on cardiomyocytes in rabbits with heart failure and its possible mechanism. Sixty New Zealand white rabbits were randomly divided into infarction group and non-infarction group, 30 in each group. Myocardial infarction was constructed by ligation of anterior descending branch of coronary artery. Coronary artery threading without ligation after thoracotomy was performed for rabbits in non-infarction group. After model construction, rabbits in each group were further divided into control group $(n=15)$ and metoprolol group $(n=15)$, and fed with normal diet and normal diet + metoprolol. Animals were sacrificed 8 weeks later, and ventricular tissue around infarction area was collected. Expression of connexin 43 (Cx43) in myocardium was detected by immunohistochemistry. Expression of $\mathrm{Cx} 43$ protein and mRNA in each group was detected by western blot and reverse transcription PCR. The $\mathrm{Cx} 43$ protein was positively expressed in non-infarction group and was evenly distributed in intercellular space. Compared with non-infarction group, expression of $\mathrm{Cx} 43$ in infarction group was significantly decreased or even disappeared, while the decrease in expression level of $\mathrm{Cx} 43$ and the degree of dispersion were lower in metoprolol group than in control group. There was no significant difference in expression of level of Cx43 protein and mRNA between the subgroups of non-infarction group $(\mathrm{P}>0.05)$. In infarction group, expression level of $\mathrm{Cx} 43$ protein and mRNA in the metoprolol group were significantly higher than those in control group $(\mathrm{P}<0.05)$. The results showed that metoprolol can protect cardiomyocytes after myocardial infarction, and the possible mechanism is related to the regulation of $\mathrm{Cx} 43$ expression in cardiomyocytes.
\end{abstract}

Correspondence to: Dr Yu Wang, Department of Cardiology, Tianjin Third Central Hospital, 83 Jintang Road, Hedong, Tianjin 300170, P.R. China

E-mail: wangy8n@163.com

Key words: myocardial infarction, metoprolol, connexin 43

\section{Introduction}

Myocardial infarction is a common clinical heart disease, and patients are often combined with arrhythmia. Ventricular fibrillation may occur in some severe cases, even leading to sudden death (1-4). Studies have found that metoprolol can inhibit arrhythmia by inhibiting sodium channels, which in turn reduced the morbidity and mortality (5-7). However, the mechanism is still unclear. In recent years, studies have shown that connexin 43 (Cx43) plays an important role in the development of myocardial infarction. Besides excitement of cardiomyocytes, electrical coupling obstruction is generally believed to be another important mechanism of myocardial infarction, and changes in the number and distribution of $\mathrm{Cx} 43$ can cause cardiomyocyte electrical coupling disorder (8). Therefore, we established a model of cardiac infarction to study the effect of metoprolol on $\mathrm{C} x 43$ expression.

\section{Materials and methods}

Materials. Sixty male New Zealand large white male rabbits (2.5-2.8 kg) were provided by Experimental Animal Center of Dalian Medical University. Metoprolol was purchased from AstraZeneca plc (batch number: H10950118). Mouse antirabbit Cz43 (dilution, 1:500; cat. no. ab79010) and GAPDH monoclonal primary antibody (dilution, 1:500; cat. no. ab9485), goat anti-mouse horseradish labeled polyclonal secondary antibody (dilution, 1:2,000; cat. no. xab6789) were purchased from Abcam (Cambridge, MA, USA). DAB color development kit and hematoxylin were purchased from Beijing Zhongshan Golden Bridge Biotechnology Co., Ltd., Beijing, China. TRIzol reagent was purchased from Invitrogen Life Technologies (Carlsbad, CA, USA). Reverse transcription kit and PCR amplification kit were purchased from Thermo Fisher Scientific (Waltham, MA, USA). This study was approved by the Ethics Committee of Tianjin Third Central Hospital, Tianjin, China.

Animal model establishment and grouping. Sixty New Zealand white rabbits were randomly divided into infarction group and non-infarction group, 30 in each group. Rabbits in infarction group were anesthetized by injecting pentobarbital $(30 \mathrm{mg} / \mathrm{kg})$ through ear vein. The chest was opened to expose the heart, followed by ligation of anterior descending branch of coronary 


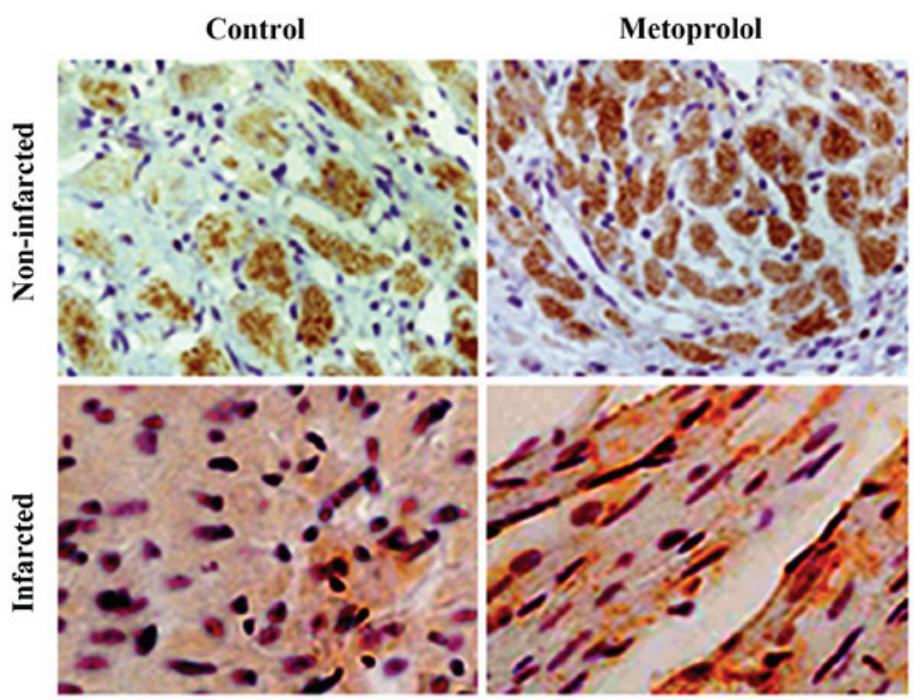

Figure 1. The expression of Cx43 in each group. Immunohistochemical results showed that Cx43 protein was strongly expressed in subgroups of non-infarction groups and distributed evenly in intercellular space.

artery. Rabbits in infarction were subjected to Sham operation after anesthesia by injecting pentobarbital $(30 \mathrm{mg} / \mathrm{kg})$ through ear vein, the chest was opened to expose the heart, followed by coronary artery threading without ligation. The elevation of $0.2 \mathrm{mV}$ at ST segment observed by ECG indicated the successfully established model. After model construction, rabbits in each group were further divided into control group $(n=15)$ and metoprolol group $(n=15)$, and fed with normal diet and normal diet + metoprolol. Animals were sacrificed 8 weeks later, and ventricular tissue around infarction area was collected.

\section{Observation indicators}

Immunohistochemical method to detect the expression of Cx43 in cardiomyocytes. Cardiac tissue was fixed in $4 \%$ paraformaldehyde, followed by hydration and embedding. The embedded tissue was cut into $4 \mu \mathrm{m}$ sections, and the expression of $\mathrm{Cx} 43$ in cardiomyocytes was detected by immunohistochemical SP method. The tissue sections were incubated with $\mathrm{Cx} 43$ monoclonal antibody (1:300, Abcam) overnight at $4^{\circ} \mathrm{C}$, followed by incubation with secondary antibody at $37^{\circ} \mathrm{C}$ for $1 \mathrm{~h}$. Then DAB staining and hematoxylin counter staining were applied. PBS was used to replace primary antibody to serve as negative control. Six visual fields were selected under an upright microscope (LSM780, Zeiss, Jena, Germany). ImageJ software was used to analyze the average positive expression area and integral optical density of the image. The method of the calculation of the average positive expression area: the number of Cx43 positive gap junctions of 6 visual fields was counted and the total number was calculated, finally, the positive area of 6 visual fields was measured (9).

Western blotting to detect the expression of Cx43 protein in cardiomyocytes. Ventricular tissue around infraction area was collected and total protein was collected using RAPI lysate, followed by quantification by coomassie blue method. Protein samples $(30 \mu \mathrm{g})$ were subjected to electrophoresis using $10 \%$ SDS-PAGE for $1.5 \mathrm{~h}$, followed by transmembrane to PVDF membrane. After blocking with $5 \%$ skimmed milk at room temperature for $1 \mathrm{~h}$, membrane was incubated with $\mathrm{Cx} 43$ monoclonal antibody $(1: 2,000)$ overnight at $4^{\circ} \mathrm{C}$. After washing with $\mathrm{PBS}$, membrane was incubated with secondary antibody [ $\operatorname{IgG}(1: 2,000)]$ at $37^{\circ} \mathrm{C}$ for $2 \mathrm{~h}$. After electrochemiluminescence development, the optical densities of the protein bands were measured by a gel imaging analysis system (Bio-Rad, Hercules, CA, USA). GAPDH was used as endogenous control. The ratio of the optical density of $\mathrm{Cx} 43$ to GAPDH protein was used as the relative expression level of $\mathrm{Cx} 43$.

Reverse transcription PCR (RT-PCR) to detect the expression of CX43 mRNA in cardiomyocytes. Ventricular tissue around infraction area was collected and total RNA was extracted using Trizol reagent. Reverse transcription was performed to synthesize cDNA, followed by PCR. The following primers were used in PCR reaction: 5'-AAGAGACCCCTGCCCACAT-3' (upstream) and 5-AGAGACACCAACGACACCACC-3' (downstream) for Cx43; 5'-CGCCTGGAGAAAGCTGCTA-3' (upstream) and 5'-ACGACCTGGTCCTCGGTGTA-3' (downstream) for GAPDH. All primer sequences were synthesized by Sangon (Shanghai, China). RT-PCR reaction conditions are as follows: $95^{\circ} \mathrm{C}$ for $10 \mathrm{~min}$, followed by 40 cycles of $95^{\circ} \mathrm{C}$ for $30 \mathrm{sec}, 50^{\circ} \mathrm{C}$ for $30 \mathrm{sec}$ and $70^{\circ} \mathrm{C}$ for $1 \mathrm{~min}$, and $70^{\circ} \mathrm{C}$ for $10 \mathrm{~min}$. PCR product was subjected to $1 \%$ agarose gel electrophoresis and the bands were observed under a gel imaging analysis system (Bio-Rad). The relative expression of $\mathrm{Cx} 43$ was reflected by the ratio of gray value of $\mathrm{Cx} 43$ to that of GAPDH.

Statistical analysis. SPSS 22.0 software (SPSS Inc., Chicago, IL, USA) was used to analyze the data. Comparisons between two groups were analyzed by LSD t-test. Comparisons among multiple groups were performed by analysis of variance (ANOVA). $\mathrm{P}<0.05$ was considered to indicate a statistically significant difference.

\section{Results}

Cx43 immunohistochemical staining results. Cx43 protein was strongly expressed in 2 subgroups of non-infarction group and distributed evenly in intercellular space. Compared 


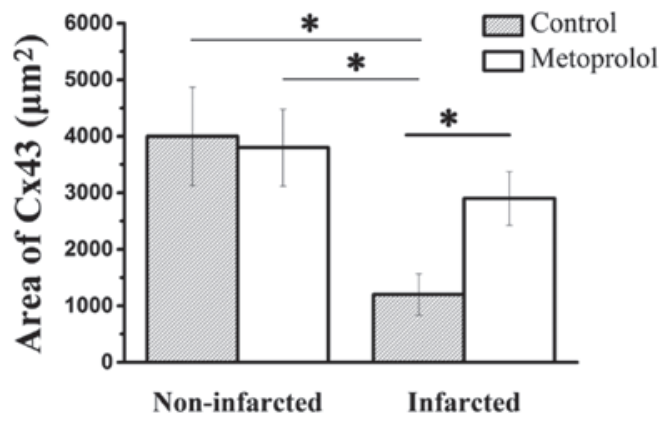

Figure 2. Comparison of the positive expression area of $\mathrm{Cx} 43$ between groups. Immunohistochemical results showed that, compared with control of infarction group, the positive expression area of $\mathrm{Cx} 43$ in the subgroups of non-infarct group and metoprolol group of infarction group was significantly increased. ${ }^{*} \mathrm{P}<0.05$

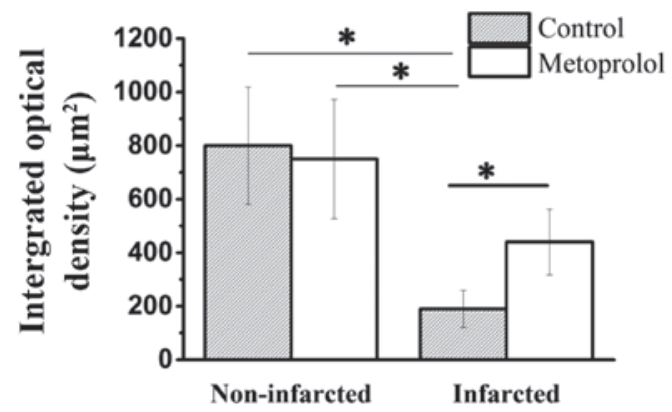

Figure 3. Comparison of $\mathrm{Cx} 43$ integral optical densities between groups Immunohistochemical results showed that, compared with control group of infarction group, $\mathrm{Cx} 43$ integral optical density in the subgroups of non-infarct group and metoprolol group of infarction group was significantly increased. ${ }^{*} \mathrm{P}<0.05$.

with non-infarction group, expression level of Cx43 was significantly decreased and Cx43 protein was irregularly distributed in infarction group. Especially in the control group of infarction group, expression of $\mathrm{Cx} 43$ was decreased or even disappeared, while the decrease in expression level of $\mathrm{Cx} 43$ and the degree of dispersion were lower in metoprolol group than in control group (Fig. 1). In infarction group, quantitative analysis showed that the positive expression area of $\mathrm{Cx} 43$ and the integral optical density value in metoprolol group were significantly higher than those in control group $(\mathrm{t}=17.483$, $\mathrm{P}=0.008 ; \mathrm{t}=17.483, \mathrm{P}=0.008)$. In non-infarction group, there was no significant difference in $\mathrm{Cx} 43$-positive expression area and integral optical density between the subgroups $(\mathrm{t}=4.381$, $\mathrm{P}=0.116 ; \mathrm{t}=1.522, \mathrm{P}=0.34$ ) (Figs. 2 and 3 ).

Compared with non-infarction group, expression level of Cx43 was significantly decreased and Cx43 protein was irregularly distributed in infarction group. Especially in the control group of infarction group, expression of $\mathrm{Cx} 43$ was decreased or even disappeared, while the decrease in expression level of Cx43 and the degree of dispersion were lower in metoprolol group than in control group.

Western blot analysis. Western blot analysis showed that there was no significant difference in the expression of $\mathrm{Cx} 43$ protein between subgroups of non-infarction group $(\mathrm{t}=4.821, \mathrm{P}=0.102$; $\mathrm{t}=3.812, \mathrm{P}=0.492)$. In infarction group, expression level of

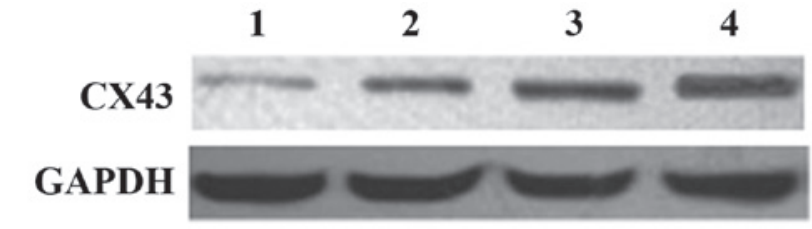

Figure 4. Western blot analysis of the expression of $\mathrm{Cx} 43$ protein in each group. Lane 1, control of infarction group; 2, control of non-infarction group; 3, metoprolol group of infarction group; 4, metoprolol group of noninfarction group.

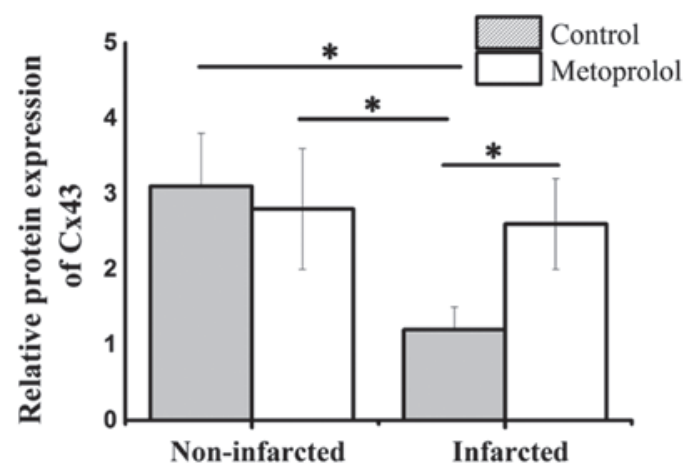

Figure 5. Expression of $\mathrm{Cx} 43$ protein in each group. Western blot results showed that the expression levels of $\mathrm{Cx} 43$ protein in the subgroups of the non-infarction group and the metoprolol group of infarction group were significantly higher than that in control group of infarction group. ${ }^{*} \mathrm{P}<0.05$.

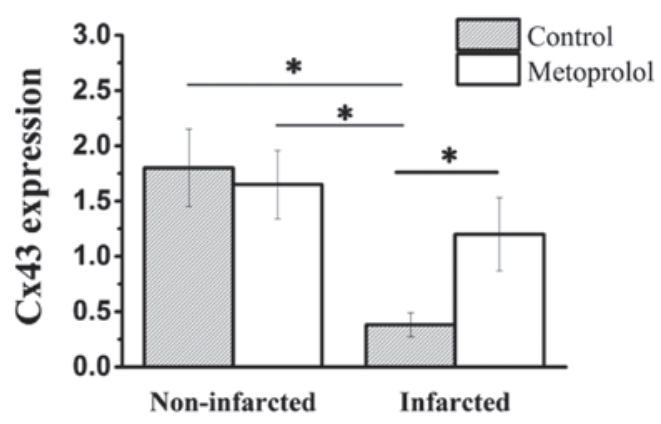

Figure 6. Expression of Cx43 mRNA in each group. Western blot results showed that the expression levels of Cx43 mRNA in the subgroups of the non-infarction group and the metoprolol group of infarction group were significantly higher than that in control group of infarction group. ${ }^{*} \mathrm{P}<0.05$.

Cx43 in control group was significantly lower than that in metoprolol group $(\mathrm{t}=12.781, \mathrm{P}=0.010)$ (Figs. 4 and 5).

$R T-P C R$ results analysis. There was no significant difference in the expression of Cx43 mRNA between the subgroups of the non-infarcted group $(\mathrm{t}=5.441, \mathrm{P}=0.091 ; \mathrm{t}=3.324, \mathrm{P}=0.212)$. In infarction group, expression level of $\mathrm{Cx} 43 \mathrm{mRNA}$ in control group was significantly lower than that in metoprolol group $(\mathrm{t}=11.261, \mathrm{P}=0.013$ ) (Fig. 6).

\section{Discussion}

Cx43 is the main constituent of gap junctions, and participates in cell-to-cell signaling $(10,11)$. Studies have found that the expression and distribution of $\mathrm{Cx} 43$ would be changed after 
myocardial infarction $(12,13)$. Peters et al (14) showed that expression and distribution of $\mathrm{Cx} 43$ protein in cardiomyocytes of the area around infarction area in dog model of myocardial infarction were changed, while the expression and distribution of $\mathrm{Cx} 43$ protein in cardiomyocytes distant from infarction area, but the expression was significantly inhibited. Results of this study showed that $\mathrm{Cx} 43$ protein was expressed and distributed evenly in intercellular space. The Cx43 positive cells are visible brown granules, which were linearly arranged in intercalated disk. Compared with non-infarction group, expression level of Cx43 was significantly decreased and Cx43 protein was irregularly distributed in infarction group. Especially in the control of infarction group, expression of Cx43 was decreased or even disappeared, while the decrease in expression level of $\mathrm{Cx} 43$ and the degree of dispersion were lower in metoprolol group than in control group. This finding is consistent with previous studies (15).

Cx43 is the main component of gap junction channel and is the main conductor of the current conduction between ventricular myocytes (16). It has been reported that $\mathrm{Cx} 43$ is one of the most important determinants of the extent of myocardial infarction after coronary artery occlusion (17). In this study, we found that the expression of $\mathrm{Cx} 43$ protein in cardiomyocytes was significantly increased by metoprolol intervention after myocardial infarction. In infarction group, positive expression area of Cx43 in metoprolol group was significantly larger than that in control group. There was no significant difference in Cx43-positive expression area and integral optical density between two subgroups of non-infarction group. Those results suggest that metoprolol can improve heart failure and cardiac insufficiency after myocardial infarction.

Lindsey et al (18) reported that the positive expression of Cx43 in model of myocardial infarction was significantly reduced, and the expression level of $\mathrm{Cx} 43$ protein was significantly lower than that of the control group, but the expression of Cx43 mRNA was not altered significantly. Results of this study showed that the distribution of $\mathrm{Cx} 43$ protein and the level of Cx43 mRNA and protein in rabbits after myocardial infarction were significantly decreased $(\mathrm{P}<0.05)$, suggesting that connexins were reconstructed after myocardial infarction, which is consistent with previous studies (19). After treatment with metoprolol, levels of Cx43 mRNA and protein in cardiomyocytes were significantly increased, suggesting that metoprolol can play a role in improving cardiac remodeling after myocardial infarction by regulating the expression of $\mathrm{Cx} 43$.

Therefore, it can be inferred from the above experimental results that metoprolol can delay the pathological changes of cardiac remodeling after myocardial infarction by regulating the expression of $\mathrm{Cx} 43$ in cardiomyocytes. However, further studies are still needed to elucidate the mechanism of the functions of metoprolol.

\section{References}

1. Karamasis G, Aljanabi F, Mohdnazri S, Jagathesan R, Kabir A, Sayer J, Robinson N, Clesham G, Aggarwal R, Gamma R, et al: TCT-386 incidence and prevention of contrast induced acute kidney injury in ST elevation myocardial infarction patients undergoing primary percutaneous coronary intervention. J Am Coll Cardiol 68: B157, 2016.
2. Priti K, Ranwa BL, Gokhroo RK, Kishore K, Bisht DS and Gupta S: Ivabradine versus metoprolol in patients with acute inferior wall myocardial infarction - 'Expanding arena for ivabradine'. Cardiovasc Ther 35: 4, 2017.

3. Zhang Y, Yang S, Liu X, Li M, Zhang W, Yang H, Hu D, Gao C and Duan G: Management of ST-segment elevation myocardial infarction in predominantly rural central China: A retrospective observational study. Medicine (Baltimore) 95: e5584, 2016.

4. Zhang D, Zhang Y, Zhao C, Zhang W, Shao G and Zhang H: Effect of lysophosphatidic acid on the immune inflammatory response and the connexin 43 protein in myocardial infarction. Exp Ther Med 11: 1617-1624, 2016.

5. Wang Y, Liu J, Suo F, Hu HS, Xue M, Cheng WJ, Xuan YL and Yan SH: Metoprolol-mediated amelioration of sympathetic nerve sprouting after myocardial infarction. Cardiology 126: 50-58, 2013.

6. Mao Y, Tokudome T, Otani K, Kishimoto I, Miyazato M and Kangawa K: Excessive sympathoactivation and deteriorated heart function after myocardial infarction in male ghrelin knockout mice. Endocrinology 154: 1854-1863, 2013.

7. Lange M, Smul TM, Redel A, Lotz C, Jazbutyte V, Schnupp V, Roewer N and Kehl F: Differential role of calcium/calmodulindependent protein kinase II in desflurane-induced preconditioning and cardioprotection by metoprolol: Metoprolol blocks desfluraneinduced preconditioning. Anesthesiology 109: 72-80, 2008.

8. Hou J, Yan P, Guo T, Xing Y, Zheng S, Zhou C, Huang H, Long $\mathrm{H}$, Zhong $\mathrm{T}$, Wu Q, et al: Cardiac stem cells transplantation enhances the expression of connexin 43 via the ANG II/AT1R/ TGF-beta1 signaling pathway in a rat model of myocardial infarction. Exp Mol Pathol 99: 693-701, 2015.

9. Xiao Y, Cai X, Atkinson A, Logantha SJ, Boyett M and Dobrzynski H: Expression of connexin 43, ion channels and $\mathrm{Ca}(2+)$-handling proteins in rat pulmonary vein cardiomyocytes. Exp Ther Med 12: 3233-3241, 2016.

10. Fu Y, Shao ZM, He QZ, Jiang BQ, Wu Y and Zhuang ZG: Hsa-miR-206 represses the proliferation and invasion of breast cancer cells by targeting Cx43. Eur Rev Med Pharmacol Sci 19: 2091-2104, 2015

11. Meraviglia V, Azzimato V, Colussi C, Florio MC, Binda A, Panariti A, Qanud K, Suffredini S, Gennaccaro L, Miragoli M, et al: Acetylation mediates $\mathrm{Cx} 43$ reduction caused by electrical stimulation. J Mol Cell Cardiol 87: 54-64, 2015.

12. Fana XZ, Zhu HJ, Wu X, Yan J, Xu J and Wang DG: Effects of doxycycline on cx43 distribution and cardiac arrhythmia susceptibility of rats after myocardial infarction. Iran J Pharm Res 13: 613-621, 2014.

13. Zhang J, Qiang CC, Li WJ, Liu LJ, Lin XX, Cheng YJ, Tang K, Yao FJ and Wu SH: Effects of Nardostachys chinensis on spontaneous ventricular arrhythmias in rats with acute myocardial infarction. J Cardiovasc Pharmacol 64: 127-133, 2014.

14. Peters NS, Coromilas J, Severs NJ and Wit AL: Disturbed connexin43 gap junction distribution correlates with the location of reentrant circuits in the epicardial border zone of healing canine infarcts that cause ventricular tachycardia. Circulation 95: 988-996, 1997.

15. Greener ID, Sasano T, Wan X, Igarashi T, Strom M, Rosenbaum DS and Donahue JK: Connexin43 gene transfer reduces ventricular tachycardia susceptibility after myocardial infarction. J Am Coll Cardiol 60: 1103-1110, 2012.

16. Hawat G, Hélie P and Baroudi G: Single intravenous low-dose injections of connexin 43 mimetic peptides protect ischemic heart in vivo against myocardial infarction. J Mol Cell Cardiol 53: 559-566, 2012.

17. Yuan MJ, Huang H, Tang YH, Wu G, Gu YW, Chen YJ and Huang CX: Effects of ghrelin on Cx43 regulation and electrical remodeling after myocardial infarction in rats. Peptides 32: 2357-2361, 2011.

18. Lindsey ML, Escobar GP, Mukherjee R, Goshorn DK, Sheats NJ, Bruce JA, Mains IM, Hendrick JK, Hewett KW, Gourdie RG, et al: Matrix metalloproteinase-7 affects connexin-43 levels, electrical conduction, and survival after myocardial infarction. Circulation 113: 2919-2928, 2006.

19. Wu T, Wu D, Wu Q, Zou B, Huang X, Cheng X, Wu Y, Hong K and Li P: Effect and mechanism of Irbesartan on occurrence of ventricular arrhythmias in rats with myocardial ischemia through connexin43 (cx43). Asian Pac J Trop Med 9: 1007-1012, 2016. 